\title{
Legume tasters: symbiotic rhizobia host preference and smart inoculant formulations
}

\section{Lisa Cangioli ${ }^{1}$, Alice Checcucci ${ }^{2}$, Alessio Mengoni ${ }^{1}$, and Camilla Fagorzi ${ }^{1}$}

1Department of Biology, University of Florence, Via Madonna del Piano, 6, Sesto Fiorentino, 50019, Italy

2Department of Agricultural and Food Science, University of Bologna,

Viale Giuseppe Fanin, 40-50, Bologna, 40127, Italy

Address correspondence and requests for materials to Camilla Fagorzi, camilla.fagorzi@unifi.it

\begin{abstract}
Mutualistic interactions have great importance in ecology, with genetic information that takes shape through interactions within the symbiotic partners and between the partners and the environment. It is known that variation of the host-associated microbiome contributes to buffer adaptation challenges of the host's physiology when facing varying environmental conditions. In agriculture, pivotal examples are symbiotic nitrogen-fixing rhizobia, known to contribute greatly to host (legume plants) adaptation and host productivity. A holistic view of increasing crop yield and resistance to biotic and abiotic stresses is that of microbiome engineering, the exploitation of a host-associated microbiome through its rationally designed manipulation with synthetic microbial communities. However, several studies highlighted that the expression of the desired phenotype in the host resides in species-specific, even genotype-specific interactions between the symbiotic partners. Consequently, there is a need to dissect such an intimate level of interaction, aiming to identify the main genetic components in both partners playing a role in symbiotic differences/host preferences. In the present paper, while briefly reviewing the knowledge and the challenges in plant-microbe interaction and rhizobial studies, we aim to promote research on genotype $x$ genotype interaction between rhizobia and host plants for a rational design of synthetic symbiotic nitrogen-fixing microbial communities to be used for sustainably improving leguminous plants yield.
\end{abstract}

Keyword: microbiome engineering, genome x genome, legume-rhizobia mutualism, symbiosis, precision agriculture

\section{Nobody is an island: the relevance of mutualistic interactions with eukaryotic hosts}

Mutualistic interactions occur everywhere in the biosphere and are pivotal in evolution, as well as having great importance in ecology (Bronstein, 2015). Mutualism involves co-evolution, innovation, change and the involvement of partners with complementary skills (Lanier et al., 2017). In 2008, the hologenome theory of evolution defined the holobiont as a unit of selection in evolution (Zilber-Rosenberg and Rosenberg, 2008). The eukaryotic host and its associated microbes are considered a superorganism, in which genetic information takes shape through interactions between the partners and between the partners and the environment (Wilson and Sober, 1989; Zilber-Rosenberg and Rosenberg, 2008). For example, plants and animals have extended their metabolic repertoire through the establishment of specific microbial communities associated to roots and gut, respectively. These microbial communities are characterized by the presence of bacteria, archaea, fungi, oomycetes, as well as viruses, and they can be partly considered as the host's extended genome, improving the nutrient acquisition process

\footnotetext{
Copyright: (c) 2021 Cangioli et al. This is an open-access article distributed unde the terms of the License Agreement with permits to the authors unrestricted distribution, and self-archiving free of charge.

Funding: This work was supported by the grant MICRO4Legumes ("II microbioma vegetale simbionte come strumento per il miglioramento delle leguminose foraggere. Acronimo"), D.M.n.89267 (Italian Ministry of Agriculture).

Competing interests: The authors have
declared that no competing interests exist.

Competing interests: The authors have
declared that no competing interests exist.

Mengoni, A., and Fagorzi, C. 2021. Legume and smart inoculant formulations. org/10.21638/spbu03.2021.106 Alice Checcucci, PhD, Research Fellow, orcid.org/0000-0002-0019-0997; Alessio of Laboratory, orcid.org/0000-0002-1265Department of Genetics and Biotechnology, University, Saint Petersburg, Russia

Revised: December 21, 2020;
}

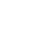

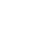


in the animal gut and in plant roots (Turner et al., 2013; Hacquard et al., 2015). However, how this can imply coevolution and consideration of the holobiont as a unit of selection is still hotly debated (Moran and Sloan, 2015; Koskella and Bergelson, 2020). Indeed, the host-associated microbiota is not fully stable, and rapid variation in its composition and functioning can take place. Such variations may contribute to buffer adaptation challenges of the host's physiology when facing varying environmental conditions. In other words, the holobiont can allow more time-effective adaption in rapidly changing environments, reducing the actual selective pressure on the host genome (Zilber-Rosenberg and Rosenberg, 2008; Rosenberg and Zilber-Rosenberg, 2016).

Interactions between the host and microbes are shaped by multiple factors associated with host immunity, phylogeny, environmental features (e.g., $\mathrm{pH}$, presence of biotic or abiotic compounds, temperature), diet and nutrient availability (Brinker et al., 2019).

Classically, plant domestication has involved selection of varieties on the basis of phenotypic features relevant to the farmer and adapted to the agricultural practices, without considering the associated microbiota. Since crops mostly rely on external inputs (e.g., fertilizers) and not on associated microbes, a decrease of microbiota diversity has been observed (EscuderoMartinez and Bulgarelli, 2019; Martínez-Romero et al., 2020), reducing the buffering effect offered by a diverse holobiont. For instance, in legumes it has been demonstrated that in the wild-growing varieties the symbiotic potential is usually higher than in commercial ones (Provorov and Tikhonovich, 2003).

Good diversity at the holobiont level may then be crucial in the search for environmentally sustainable crop production. Here, the authors explored the knowledge and challenges in the promotion of a rational use of symbiotic nitrogen-fixing bacteria for leguminous plant growth.

\section{Biotechnology on the holobiont: cracking the microbiome}

The increase of the human world population in the last years (currently 7 billion people, with 9 billion people expected by 2050) has led to the need to increase agricultural production (FAO; 2018). Inorganic nitrogen fertilizers are required to increase field production, but the excessive use of these compounds has deleterious effects on the environment (Yang and Fang, 2015; Zheng et al., 2019).

One of the possible alternative and sustainable approaches to enrich fields with nitrogen is the inoculation of crops with microorganisms able to promote the plant growth and health, the so-called Plant Growth Promoting Microorganisms (PGPM) (Lucy et al., 2004;
Schlaeppi and Bulgarelli, 2015). In particular, Plant Growth Promoting Rhizobacteria (PGPR) can be applied as biocontrol agents, bio-inoculants and bio-fertilizers (Bloemberg and Lugtenberg, 2001). PGPM and PGPR constitute a relevant fraction of the plant mutualistic microbiome. They thrive on and within plants, using plant-produced organic molecules for their growth and "rewarding" the host with increased nutrient availability for the root apparatus as well as additional phytohormones (Werner et al., 2014).

Modification of the plant-associated microbiome (mainly, but not only, involving PGPR) has an effective potential to improve plant yield and resistance to biotic and abiotic stresses; this potential is stirring the attention of many investigators (Turner et al., 2013). This approach of "microbiome engineering" is based on reconstructing synthetic microbial communities after laboratory selection of microbes with the best ability to deliver PGP traits to the plants (Ke et al., 2020). The principal aims of microbiome manipulation are to: 1 ) reduce the incidence of plant diseases (Malfanova, 2013) ; 2) increase agricultural production (Bakker et al., 2012); 3) reduce chemical inputs (Adesemoye et al., 2009) and 4) reduce emissions of greenhouse gases (Singh et al., 2010). These goals meet the principles of agronomic sustainability and the world's increasing population (Turner et al., 2013). To date, successful attempts have been reviewed by de Vries et al., 2020; Dubey et al., 2020; Qiu et al., 2019; and Sudheer et al., 2020.

\section{Legume-rhizobia mutualism as a model}

Among the "rewards" from microbes, assimilable nitrogen compounds are one of the key components: the supply of nitrogen in the soil represents the classical limiting factors of plant productivity (Fageria and Baligar, 2005). Bacteria called rhizobia are the typical example of PGPM which provides the host plant assimilable nitrogen. Through a process called biological nitrogen fixation (BNF), involving several genes and signaling molecules, rhizobia fix atmospheric nitrogen into compounds assimilable by plants. The BNF is a paradigmatic example of mutualistic association between plants and bacteria. The symbiotic BNF (SNF, Symbiotic Nitrogen Fixation) is a facultative symbiotic association involving rhizobia (bacteria from Alfa- and Betaproteobacteria classes) and some actinobacteria (Frankia spp.), which associate with plants from the Fabales (Leguminosae), Fagales, Cucurbitales and Rosales orders (Pawlowski and Newton, 2008; Griesmann et al., 2018). During the symbiotic interaction, bacteria induce the formation of a specific structure at the root level, the nodule, then colonize nodule plant cells intracellularly and activate the key component of BNF (i.e., the nitrogenase enzyme), producing ammonia, which is then exchanged for the 
photosynthetic products with the host plant (Kereszt et al., 2011).

The symbiosis between legumes and rhizobia is the most diffused and relevant in providing fixed nitrogen to agroecosystems. This interaction is mediated by a plethora of molecular signals that direct bacterial invasion, modulate the host defence response, permit the intracellular colonization, guide the regulation of the cell cycle and regulate the nutrient exchange (Jones et al., 2007; Gibson et al., 2008). One of the most essential signalling compounds produced by rhizobia is the Nod Factor (NF). Rhizobia are able to produce Nod factors characterized by different structures which, consequently, are recognized by specific host plant receptors (Geurts and Bisseling, 2002). Due to this process, evidence has emerged for coevolution between rhizobia and host plant at the population level (Igolkina et al., 2019). However, restricted host specificity is present, and phylogenetical studies confirmed that the limited host range evolved from an ancestral broad range mutualism (Pueppke and Broughton, 1999). Therefore, evolution has shaped the two partners toward species-specific and even strain-specific interactions allowing plant selection for the best beneficial symbionts (Checcucci et al., 2016; Remigi et al., 2016; Westhoek et al., 2017; Sachs et al., 2018).

The two-way exchange of benefits between plant roots and rhizobia offers us the basic knowledge to mold and manipulate this symbiosis interaction, sustaining the ecological and agronomic practices in agricultural systems (Bakker et al., 2012; Checcucci et al., 2017; Soumare et al., 2020).

\section{Forming the symbiotic structure: recognition of the good partners}

The multi-step process which allows the symbiotic interaction between nitrogen-fixing rhizobia and leguminous plants is highly regulated, to allow the selection by the plant of the most effective (highly rewarding) partners (Sachs et al., 2018). Many genes and mechanisms involved in the establishment of the symbiosis between rhizobia and host legumes have been identified (Roy et al., 2020).

The early events start with the exchange of signals between the nitrogen-fixing rhizobia and the plant in the rhizosphere. Here, the first specific signals are found in compounds present in root exudates (flavonoids), which bind receptor proteins in the rhizobial cell (NodD). Activated NodD trigger bacterial nod genes expression which lead to synthesis of the Nod factor (a lipochitooligosaccharide molecule), which is then secreted by the bacterial cell. The perception of the Nod factor by the plant roots induces developmental changes such as root hair curling, membrane depolarization, intracellular calcium oscillations, and the initiation of cell division in the root cortex, which establishes a meristem and nodule primor- dium (Liu et al., 2020). Species-specific early recognition is based on the fact that different rhizobial species and strains can have differential activation by flavonoids on NodD proteins and may produce different Nod factor molecules. Different Nod factors are then specifically recognized by plant receptors (LysM), ensuring species-specific recognition on the plant side (Bozsoki et al., 2020).

When the dialogue between plant roots and rhizobia is successful, a small number of bacteria are trapped by the root hair, which begins an inverse tip growth, forming a long and narrow passage called the "infection thread". The bacteria reach the root cortex as the final destination and reacquire properties of stem cells, which form the lateral organ nodule. The bacteria infect the nodule, enter the cytoplasm of plant cells and differentiate into a distinct cell type called bacteroid, which can fix atmospheric nitrogen into ammonia, establishing an intricate metabolic interchange with the host plant (diCenzo et al., 2020; Roy et al., 2020). Moreover here, nodules where rhizobia fail to produce fixed nitrogen are sanctioned, ensuring that only good mutualist rhizobia are allowed to thrive in root nodules (Kiers and Denison, 2008), though cheating may occur (Checcucci et al., 2016). Though molecular details of sanctions are still elusive, molecular determinants of species-specificity have been discovered. For instance, in the model legume Medicago truncatula, the plant response after bacteria invasion of the host cell is modulated by two nodule-specific cysteine-rich (NCR) peptides encoded by the genes NFS1 and NFS2 (Wang et al., 2018; Tirichine et al., 2000). More recently, again in M.truncatula, MtNPD1, a nodule-specific polycistin lipogenase, has been shown to represent an important determinant of host-strain specificity, with particular regard to plant invasion and nitrogen fixation (Pislariu et al., 2019). Functional symbiotic compatibility between Mesorhizobium loti and Lotus japonicum is determined by the presence of the nepenthesin-type aspartic peptidase nodule-induced LjAPN1 (Yamaya-Ito et al., 2018).

In Pisum sativum, Nod factors perception is mediated by the gene PsSym2, which probably encodes a LysMRLK. PsSym 2 was the first discovered symbiosis-related pea gene and it determines increased selectivity toward rhizobia in the pea cv. Afghanistan (Sulima et al., 2017).

\section{The role of genotype $x$ genotype interactions in shaping the symbiotic partnership}

Interactions between different species with different genotypes imply the expression of a phenotype that depends on the interacting organisms (Bose and Schulte, 2014). The effects of (microbial) genotype (G) $\mathrm{x}$ (host) genotype $(\mathrm{G})$ interactions can be relevant for both rate and direction of evolutionary selection (Wade, 2007) and have clear importance for rational improvement of plant-rhizobium 


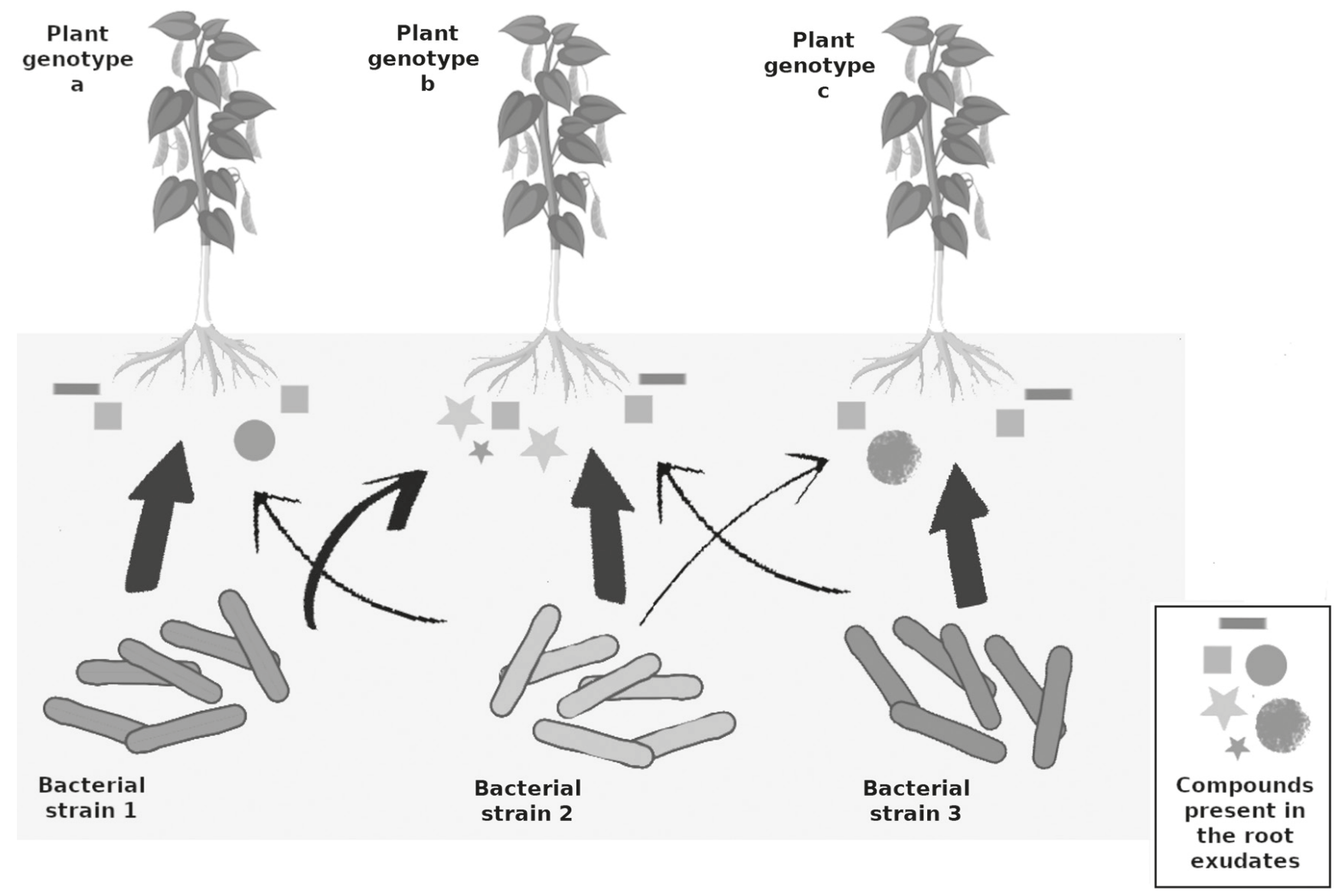

Fig. 1. Simplified model of genotype $x$ genotype rhizobia-legume interaction. Different genotypes of the same species of legume interact with different genotypes of the same rhizobial species. Interactions can be trained by the expression of an intricate network of genes of both symbiotic partners, driving host preference. The rhizobial strain can initiate a mutualistic relationship with multiple legume genotypes, but specific genotype $x$ genotype interaction can result in a more effective symbiotic ability. In the figure, the effectiveness of symbiotic ability is represented by arrows of different thickness (arrows are thicker when symbiosis is more effective) and compounds produced by the different plant genotypes are represented by the symbols near the root system (symbols of the same colour of the bacterial strain are responsible for a more effective symbiotic relationship).

symbiosis. As reviewed above, the development and application of genetic and genomic tools has made it possible to dissect in great detail the molecular determinants involved in plant-microbe interaction (Levy et al., 2018) and rhizobial symbioses (diCenzo et al., 2019).

However, most of the studies involved model strains and plants and their respective mutants, with only a limited evaluation of the genetic bases of the somewhat large phenotypic variation in the symbiotic phenotype due to natural genotype variation. Early studies in the alfalfa rhizobial symbiont Sinorhizobium meliloti showed that plant variety exerts a detectable effect on the recruitment of native soil rhizobial population (Carelli et al., 2000; Paffetti et al., s.d.). Clearly, the fitness advantage of the symbiosis (Burghardt, 2020) is influenced by GxG interactions between the two (or more) partners (Heath, 2008). Recently, the use a "select and resequence" approach has disclosed some of the determinants of $\mathrm{GxG}$ interaction in the model symbiosis between strains of Sinorhizobium meliloti and genotypes of the legume the Medicago truncatula (Burghardt et al., 2018, 2020). With a similar aim, a recent study has been conducted to analyse at the gene expression level the genotype-based variation of the interaction, using $S$. meliloti and the forage legume M. sativa (Kang et al., 2020). In this last work, the transcriptional profile of alfalfa inoculated with different S. meliloti strains was investigated, finding that the plant differentially expressed genes depending on the S. meliloti strain tested. Among the candidate genes influenced by the rhizobial strain genotype, genes encoding nodulins, NCR peptides and proteins belonging to the NBS-LRR family were identified (Kang et al., 2020). On the rhizobial side we recently sequenced the transcriptome of several S. meliloti strains incubated in the presence of root exudates of different alfalfa varieties. Results showed an intricate network of genes whose expression is influenced by the genotype of both symbiotic partners, suggesting the presence of a large number of determinants involved in $\mathrm{GxG}$ interactions which can have an impact on the outcome of the rhizobium-legume symbiosis (Fig. 1) (Fagorzi et al., 2021). Dissection of such a complex network, iden- 
tifying the main components playing a role in symbiotic differences/host preferences, will make it possible to rationally screen and genetically improve the most promising plant and symbiotic bacteria partnerships, as well as to better understand the intricate routes of the evolution of symbioses.

On the plant side, the GxG interactions between selected nitrogen-fixing rhizobia and selected symbiotically active plant genotypes also lend advantages in terms of plant productivity (Provorov \& Tikhonovich, 2003).

\section{Holobiont improvement programs toward precision agriculture}

Classical studies, such as the ones performed by Bliss (1990) and Barnes et al. (1984), showed the importance of a multidisciplinary approach to improve the symbiotic activity in Phaseolus vulgaris and Medicago sativa.

The study of plant genotype and breeding programs have been fundamental in understanding plant physiological traits and find directions for productivity improvement. The use of fertilizers can definitely be reduced by exploiting the knowledge of a plant's genome, soil conditions and plant-associated microorganisms. Indeed, genome editing methods allow targeted modification in the plant genotype, making it possible to improve and adapt a crop's genetic traits with the current soil characteristics (Joseph et al., 2020), including rhizosphere resident bacteria and fungi. The advantages of this technological and biological knowledge in the agricultural field were recently discussed in two workshops organized by the USDA National Institute of Food and Agriculture (NIFA)-funded Big Data Driven Agriculture, where the importance of their applicability was assessed on the basis of standardized protocol applications, funding opportunities and involvement of a broader scientific community and farmers (Shakoor et al., 2019). Currently, high-throughput techniques for plants and soil phenotyping, tools for the measurement of crop productivity, genome editing methods, breeding and microbial inoculation technologies form the basis of precision agriculture, which involves both soil/plant science experts and farm management operators.

For SNF, besides the biotic factors shaping legumerhizobia nitrogen fixation (e.g., selection and interaction with the partner, competition with indigenous microorganisms), abiotic variables can strongly influence the success of the symbiosis. Indeed, nutrient availability, extreme temperature, $\mathrm{pH}$, salinity and drought (Bellabarba et al., 2019) challenge legume crops, stimulating the need for an adjustable agriculture. Precision agriculture can ensure the health and productivity of soil and crops through knowledge and technology advancements, guaranteeing protection and well-being of the environment.
Presently, several diagnostic methods are based on the quantification of nitrogen in legumes, evaluating the effectiveness of rhizobial symbiosis (e.g., measures of nitrogen at the leaf level and measurement of nitrogen abundance in plant tissues through isotope-based methodologies (Thilakarathna and Raizada, 2018). Furthermore, several technologies aimed to optimize biological nitrogen fixation in the field are based on the diagnosis of soil traits (composition, structure, organic matter, landscape position and micronutrients concentration).

The introduction of beneficial microorganisms through crop inoculation is now becoming popular among farmers, both in organic farming and unconventional agricultural practices. Nevertheless, the tuning of inoculants consistent with indigenous PGPM residents in the soil still faces a challenge in precision agriculture (Thilakarathna and Raizada, 2018).

Actually, the success of microbial inoculants' performance can be increased by precision farming methods, such as fertigation, which delivers the bioinoculants in the root area, thereby minimizing loss and interference with other liquid chemical inputs such as fertilizers, herbicides, pesticides and growth hormones, still used periodically (Bharathi et al., 2017). Furthermore, seed coating is widely used in agricultural practice, thanks to its beneficial impact on seed performance and plant productivity. Among coating agents, chemical pesticides, micronutrients, bio-stimulants and marker substances (tracing seeds within the crop supply chain) can be included. However, microbial (including bacteria and fungi) seed coating has been considered a cheap and efficient method for the delivery of inoculants. Recent research in precision agriculture has mainly focused on the optimization of such coating, setting up formulation of multi-effect microbial consortia designed for the already targeted annual crops (such as cereals, legumes, and some vegetables) and/or developed for other agricultural products.

However, it is becoming clear that, apart from soil and climatic features, which determine the choice of a specific plant variety by the farmer, the symbiotic rhizobia (as the other inoculants) genotypes matter. As reported above, GxG effects are present, determining the competitive abilities of the inoculant against the indigenous rhizobial populations. As for genetic screening and breeding programs for crops, there is a need for similar strategies for the symbiotic rhizobia. Several collections of rhizobia are present in the world, such as those at the USDA in the USA, the Centre for Rhizobium Studies (CRS) in Australia or at ARRIAM in the Russian Federation. Genome sequencing programs (e.g., GEBA at DOE-JGI, USA) and analysis of strain genotypes have been conducted. For instance, in S. meliloti, more than 280 high quality genome sequences are available on the GenBank database (October 2020). However, informa- 
tion on the set of genes linked to the variation in symbiotic partnership performances (such as $\mathrm{GxG}$ ) are still in their infancy. We need more comprehensive, holobiontcentered and systems biology-oriented studies to provide the basis for a future integration into plant breeding programs, concurrent symbiotic "breeding" programs, resulting in outperformance of the symbiotic partnership.

\section{References}

Adesemoye, A. O., Torbert, H. A., and Kloepper, J. W. 2009. Plant growth-promoting rhizobacteria allow reduced application rates of chemical fertilizers. Microbial Ecology 58(4):921929. https://doi.org/10.1007/s00248-009-9531-y

Bakker, M. G., Manter, D. K., Sheflin, A. M., Weir, T. L., and Vivanco, J. M. 2012. Harnessing the rhizosphere microbiome through plant breeding and agricultural management. Plant and Soil 360(1-2):1-13. https://doi. org/10.1007/s11104-012-1361-x

Barnes, D., Heichel, G., Vance, C., and Ellis, W. 1984. A multiple-trait breeding program for improving the symbiosis for $\mathrm{N}_{2}$ fixation between Medicago sativa $\mathrm{L}$. and Rhizobium meliloti. Plant and Soil 82(3):303-314. https://doi. org/10.1007/BF02184269

Bellabarba, A., Fagorzi, C., diCenzo, G. C., Pini, F., Viti, C., and Checcucci, A. 2019. Deciphering the symbiotic plant microbiome: translating the most recent discoveries on rhizobia for the improvement of agricultural practices in metal-contaminated and high saline lands. Agronomy 9(9):529. https://doi.org/10.3390/agronomy9090529

Bharathi, J., Balachander, D., Kumar, K., and Narayanan, R. 2017. Evaluation of new microbial consortium through biofertigation for precision farming of bhendi ( $\mathrm{COBH} 1)$. International Journal of Medical Sciences and Pharmaceutical Research 1(1):15-24.

Bliss, F. 1990. Utilization of genetic resources for crop improvement: The common bean. In: Brown, A. H.D., Clegg, M.T., Kahler, A.L., and Weir, B.S.(Eds.), Plant population genetics, breeding, and genetic resources, pp. 317-333, Sinauer, Sunderland, MA.

Bloemberg, G. V. and Lugtenberg, B. J.J. 2001. Molecular basis of plant growth promotion and biocontrol by rhizobacteria. Current Opinion in Plant Biology 4(4):343-350. https://doi.org/10.1016/S1369-5266(00)00183-7

Bose, J. and Schulte, R.D. 2014. Testing GxG interactions between coinfecting microbial parasite genotypes within hosts. Frontiers in Genetics 5:124. https://doi. org/10.3389/fgene.2014.00124

Bozsoki, Z., Gysel, K., Hansen, S. B., Lironi, D., Krönauer, C., Feng, F., de Jong, N., Vinther, M., Kamble, M., Thygesen, M. B., Engholm, E., Kofoed, C., Fort, S., Sullivan, J.T., Ronson, C. W., Jensen, K.J., Blaise, M., Oldroyd, G., Stougaard, J., ... Radutoiu, S. 2020. Ligandrecognizing motifs in plant LysM receptors are major determinants of specificity. Science 369(6504):663-670. https://doi.org/10.1126/science.abb3377

Brinker, P., Fontaine, M. C., Beukeboom, L.W., and Falcao Salles, J. 2019. Host, symbionts, and the microbiome: The missing tripartite interaction. Trends in $\mathrm{Mi}$ crobiology 27(6):480-488. https://doi.org/10.1016/j. tim.2019.02.002

Bronstein, J.L. 2015. Mutualism. Oxford University Press, USA. https://doi.org/10.1093/acprof:oso/9780199675654.001.0001

Burghardt, L.T. 2020. Evolving together, evolving apart: Measuring the fitness of rhizobial bacteria in and out of symbiosis with leguminous plants. New Phytologist 228(1):28-34. https://doi.org/10.1111/nph.16045

Burghardt, L. T., Epstein, B., Guhlin, J., Nelson, M.S., TayIor, M. R., Young, N. D., Sadowsky, M. J., and Tiffin, P. 2018. Select and resequence reveals relative fitness of bacteria in symbiotic and free-living environments. Proceedings of the National Academy of Sciences USA 115(10):2425-2430. https://doi.org/10.1073/pnas.1714246115

Burghardt, L.T., Trujillo, D.I., Epstein, B., Tiffin, P., and Young, N. D. 2020. A select and resequence approach reveals strain-specific effects of Medicago nodule-specific PLAT-domain genes. Plant Physiology 182(1):463-471. https://doi.org/10.1104/pp.19.00831

Carelli, M., Gnocchi, S., Fancelli, S., Mengoni, A., Paffetti, D., Scotti, C., and Bazzicalupo, M. 2000. Genetic diversity and dynamics of Sinorhizobium meliloti populations nodulating different alfalfa cultivars in Italian soils. Applied and Environmental Microbiology 66(11):4785-4789. https://doi.org/10.1128/AEM.66.11.4785-4789.2000

Checcucci, A., Azzarello, E., Bazzicalupo, M., Galardini, M., Lagomarsino, A., Mancuso, S., Marti, L., Marzano, M. C., Mocali, S., Squartini, A., Zanardo, M., and Mengoni, A. 2016. Mixed nodule infection in Sinorhizobium meliloti-Medicago sativa symbiosis suggest the presence of cheating behavior. Frontiers in Plant Science 7:835. https://doi. org/10.3389/fpls.2016.00835

Checcucci, A., DiCenzo, G. C., Bazzicalupo, M., and Mengoni, A. 2017. Trade, diplomacy, and warfare: The quest for elite rhizobia inoculant strains. Frontiers in Microbiology 8:2207. https://doi.org/10.3389/fmicb.2017.02207

de Vries, F.T., Griffiths, R. I., Knight, C. G., Nicolitch, O., and Williams, A. 2020. Harnessing rhizosphere microbiomes for drought-resilient crop production. Science 368(6488):270-274. https://doi.org/10.1126/science. aaz5192

diCenzo, G. C., Tesi, M., Pfau, T., Mengoni, A., and Fondi, M. 2020. Genome-scale metabolic reconstruction of the symbiosis between a leguminous plant and a nitrogen-fixing bacterium. Nature Communications 11(1):2574. https://doi.org/10.1038/s41467-020-16484-2

diCenzo, G. C., Zamani, M., Checcucci, A., Fondi, M., Griffitts, J.S., Finan, T. M., and Mengoni, A. 2019. Multidisciplinary approaches for studying rhizobium-legume symbioses. Canadian Journal of Microbiology 65(1):1-33. https://doi.org/10.1139/cjm-2018-0377

Dubey, R. K., Tripathi, V., Prabha, R., Chaurasia, R., Singh, D. P., Rao, C. S., El-Keblawy, A., and Abhilash, P. C. 2020. Unravelling the soil microbiome: Perspectives for environmental sustainability. Springer. https://doi.org/10.1007/9783-030-15516-2

Escudero-Martinez, C. and Bulgarelli, D. 2019. Tracing the evolutionary routes of plant-microbiota interactions. Current Opinion in Microbiology 49:34-40. https://doi. org/10.1016/j.mib.2019.09.013

Fageria, N. and Baligar, V. 2005. Enhancing nitrogen use efficiency in crop plants. Advances in Agronomy 88:97-185. https://doi.org/10.1016/S0065-2113(05)88004-6

Fagorzi, C., Bacci, G., Huang, R., Cangioli, L., Checcucci, A., Fini, M., Perrin, E., Natali, C., diCenzo, G. C., and Mengoni, A. 2021. Non-additive transcriptomic signatures of genotype $x$ genotype interactions during the initiation of plant-rhizobium symbiosis. mSystems 6(1):e00974-20. https://doi.org/10.1128/mSystems.00974-20

Geurts, R. and Bisseling, T. 2002. Rhizobium nod factor perception and signalling. The Plant Cell 14(suppl 1):S239. https://doi.org/10.1105/tpc.002451

Gibson, K. E., Kobayashi, H., and Walker, G. C. 2008. Molecular determinants of a symbiotic chronic infection. Annual Re- 
view of Genetics 42(1):413-441. https://doi.org/10.1146/ annurev.genet.42.110807.091427

Griesmann, M., Chang, Y., Liu, X., Song, Y., Haberer, G., Crook, M. B., Billault-Penneteau, B., Lauressergues, D., Keller, J., Imanishi, L., Roswanjaya, Y. P., Kohlen, W., Pujic, P., Battenberg, K., Alloisio, N., Liang, Y., Hilhorst, H., Salgado, M. G., Hocher, V., ... Cheng, S. 2018. Phylogenomics reveals multiple losses of nitrogen-fixing root nodule symbiosis. Science 361(6398):eaat1743. https:// doi.org/10.1126/science.aat1743

Hacquard, S., Garrido-Oter, R., González, A., Spaepen, S., Ackermann, G., Lebeis, S., McHardy, A. C., Dangl, J. L., Knight, R., Ley, R., and Schulze-Lefert, P. 2015. Microbiota and host nutrition across Plant and Animal Kingdoms. Cell Host and Microbe 17(5):603-616. https://doi. org/10.1016/j.chom.2015.04.009

Heath, K. D. 2008. The coevolutionary genetics of plant-microbe interactions. New Phytologist 180(2):268-270. https://doi.org/10.1111/j.1469-8137.2008.02633.x

Igolkina, A.A., Bazykin, G.A., Chizhevskaya, E.P., Provorov, N.A., and Andronov, E. E. 2019. Matching population diversity of rhizobial nod A and legume NFR5 genes in plant-microbe symbiosis. Ecology and Evolution 9(18):10377-10386. https://doi.org/10.1002/ece3.5556

Jones, K. M., Kobayashi, H., Davies, B.W., Taga, M. E., and Walker, G.C. 2007. How rhizobial symbionts invade plants: The Sinorhizobium-Medicago model. Nature Reviews Microbiology 5(8):619-633. https://doi.org/10.1038/ nrmicro1705

Joseph, A., Chandra, J., and Siddharthan, S. 2020. Genome analysis for precision agriculture using artificial intelligence: $A$ survey. In Data Science and Security, pp. 221-226. Springer. https://doi.org/10.1007/978-981-15-5309-7_23

Kang, W., Jiang, Z., Chen, Y., Wu, F., Liu, C., Wang, H., Shi, S., and Zhang, X.-X. 2020. Plant transcriptome analysis reveals specific molecular interactions between alfalfa and its rhizobial symbionts below the species level. $B M C$ Plant Biology 20(1):293. https://doi.org/10.1186/s12870020-02503-3

Ke, J., Wang, B., and Yoshikuni, Y. 2020. Microbiome engineering: synthetic biology of plant-associated microbiomes in sustainable agriculture. Trends in Biotechnology. https://doi.org/10.1016/j.tibtech.2020.07.008

Kereszt, A., Mergaert, P., and Kondorosi, E. 2011. Bacteroid development in legume nodules: Evolution of mutual benefit or of sacrificial victims? Molecular Plant-Microbe Interactions 24(11):1300-1309. https://doi.org/10.1094/ MPMI-06-11-0152

Kiers, E. T. and Denison, R. F. 2008. Sanctions, cooperation, and the stability of plant-rhizosphere mutualisms. Annual Review of Ecology, Evolution and Systematics 39(1):215-236. https://doi.org/10.1146/annurev.ecolsys.39.110707.173423

Koskella, B. and Bergelson, J. 2020. The study of host-microbiome (co)evolution across levels of selection. Philosophical Transactions of the Royal Society B: Biological Sciences 375(1808):20190604. https://doi.org/10.1098/ rstb.2019.0604

Lanier, K. A., Petrov, A. S., and Williams, L. D. 2017. The central symbiosis of molecular biology: Molecules in mutualism. Journal of Molecular Evolution 85(1-2):8-13. https://doi. org/10.1007/s00239-017-9804-x

Levy, A., Conway, J. M., Dangl, J. L., and Woyke, T. 2018. Elucidating bacterial gene functions in the plant microbiome. Cell Host and Microbe 24(4):475-485. https://doi. org/10.1016/j.chom.2018.09.005

Liu, S., Ratet, P., and Magne, K. 2020. Nodule diversity, evolution, organogenesis and identity. Advances in Bo- tanical Research 94:119-148. https://doi.org/10.1016/ bs.abr.2019.09.009

Lucy, M., Reed, E., and R. Glick, B. 2004. Applications of free living plant growth-promoting rhizobacteria. Antonie van Leeuwenhoek 86:1-25. https://doi.org/10.1023/B:ANTO. $0000024903.10757 .6 \mathrm{e}$

Malfanova, N. 2013. Endophytic bacteria with plant growth promoting and biocontrol abilities. Doctoral Thesis, Leiden University.

Martínez-Romero, E., Aguirre-Noyola, J.L., Taco-Taype, N., Martínez-Romero, J., and Zuñiga-Dávila, D. 2020. Plant microbiota modified by plant domestication. Systematic and Applied Microbiology 43(5):126106. https://doi. org/10.1016/j.syapm.2020.126106

Moran, N. A. and Sloan, D. B. 2015. The hologenome concept: helpful or hollow? PLOS Biology 13(12):e1002311. https:// doi.org/10.1371/journal.pbio.1002311

Paffetti, D., Daguin, F., Fancelli, S., Gnocchi, S., Lippi, F., Scotti, C., and Bazzicalupo, M. 1998. Influence of plant genotype on the selection of nodulating Sinorhizobium meliloti strains by Medicago sativa. Antonie van Leeuwenhoek 73:3-8. https://doi.org/10.1023/A:1000591719287

Pawlowski, K. and Newton, W. E. 2008. Nitrogen-fixing actinorhizal symbioses. Springer. https://doi. org/10.1007/978-1-4020-3547-0

Pislariu, C. I., Sinharoy, S., Torres-Jerez, I., Nakashima, J., Blancaflor, E. B., and Udvardi, M. K. 2019. The nodule-specific PLAT domain protein NPD1 is required for nitrogen-fixing symbiosis. Plant Physiology 180(3):1480-1497. https://doi.org/10.1104/pp.18.01613

Provorov, N. A. and Tikhonovich, I. A. 2003. Genetic resources for improving nitrogen fixation in legume-rhizobia symbiosis. Genetic Resources and Crop Evolution 50(1):89-99. https://doi.org/10.1023/A:1022957429160

Pueppke, S. G. and Broughton, W.J. 1999. Rhizobium sp. strain NGR234 and $R$. fredii USDA257 share exceptionally broad, nested host ranges. Molecular Plant-Microbe Interactions 12(4):293-318. https://doi.org/10.1094/MPMI. 1999.12.4.293

Qiu, Z., Egidi, E., Liu, H., Kaur, S., and Singh, B. K. 2019. New frontiers in agriculture productivity: Optimised microbial inoculants and in situ microbiome engineering. Biotechnology Advances 37(6):107371. https://doi.org/10.1016/j. biotechadv.2019.03.010

Remigi, P., Zhu, J., Young, J. P. W., and Masson-Boivin, C. 2016. Symbiosis within symbiosis: Evolving nitrogen-fixing legume symbionts. Trends in Microbiology 24(1):63-75. https://doi.org/10.1016/j.tim.2015.10.007

Rosenberg, E. and Zilber-Rosenberg, I. 2016. Microbes drive evolution of animals and plants: The hologenome concept. MBio 7(2):e01395-15. https://doi.org/10.1128/ mBio.01395-15

Roy, S., Liu, W., Nandety, R. S., Crook, A., Mysore, K. S., Pislariu, C. I., Frugoli, J., Dickstein, R., and Udvardi, M. K. 2020. Celebrating 20 years of genetic discoveries in legume nodulation and symbiotic nitrogen fixation. The Plant Cell 32(1):15-41. https://doi.org/10.1105/tpc.19.00279

Sachs, J. L., Quides, K. W., and Wendlandt, C. E. 2018. Legumes versus rhizobia: A model for ongoing conflict in symbiosis. New Phytologist 219(4):1199-1206. https://doi. org/10.1111/nph.15222

Schlaeppi, K. and Bulgarelli, D. 2015. The plant microbiome at work. Molecular Plant-Microbe Interactions 28(3):212217. https://doi.org/10.1094/MPMI-10-14-0334-FI

Shakoor, N., Northrup, D., Murray, S., and Mockler, T.C. 2019. Big data driven agriculture: Big data analytics in plant breeding, genomics, and the use of remote sensing technologies to advance crop productivity. The 
Plant Phenome Journal 2(1):1-8. https://doi.org/10.2135/ tppj2018.12.0009

Singh, B. K., Bardgett, R. D., Smith, P., and Reay, D. S. 2010. Microorganisms and climate change: Terrestrial feedbacks and mitigation options. Nature Reviews Microbio/ogy 8(11):779-790. https://doi.org/10.1038/nrmicro2439

Soumare, A., Diedhiou, A. G., Thuita, M., Hafidi, M., Ouhdouch, Y., Gopalakrishnan, S., and Kouisni, L. 2020. Exploiting biological nitrogen fixation: A route towards a sustainable agriculture. Plants 9(8):1011. https://doi. org/10.3390/plants9081011

Sudheer, S., Bai, R. G., Usmani, Z., and Sharma, M. 2020. Insights on engineered microbes in sustainable agriculture: Biotechnological developments and future prospects. Current Genomics 21(5):321-333. https://doi.org/1 $0.2174 / 1389202921999200603165934$

Sulima, A.S., Zhukov, V.A., Afonin, A. A., Zhernakov, A.I., Tikhonovich, I. A., and Lutova, L.A. 2017. Selection signatures in the first exon of paralogous receptor kinase genes from the Sym2 region of the Pisum sativum L. genome. Frontiers in Plant Science 8:1957. https://doi. org/10.3389/fpls.2017.01957

Thilakarathna, M. S. and Raizada, M. N. 2018. Challenges in using precision agriculture to optimize symbiotic nitrogen fixation in legumes: Progress, limitations, and future improvements needed in diagnostic testing. Agronomy 8(5):78. https://doi.org/10.3390/agronomy8050078

Tirichine, L., de Billy, F., and Huguet, T. 2000. Mtsym6, a gene conditioning Sinorhizobium strain-specific nitrogen fixation in Medicago truncatula. Plant Physiology 123(3):845852. https://doi.org/10.1104/pp.123.3.845

Turner, T.R., James, E. K., and Poole, P.S. 2013. The plant microbiome. Genome Biology 14(6):209. https://doi. org/10.1186/gb-2013-14-6-209

Wade, M.J. 2007. The co-evolutionary genetics of ecological communities. Nature Reviews Genetics 8(3):185-195. https://doi.org/10.1038/nrg2031

Wang, Q., Liu, J., Li, H., Yang, S., Körmöczi, P., Kereszt, A., and Zhu, H. 2018. Nodule-specific cysteine-rich pep- tides negatively regulate nitrogen-fixing symbiosis in a strain-specific manner in Medicago truncatula. Molecular Plant-Microbe Interactions 31(2):240-248. https://doi. org/10.1094/MPMI-08-17-0207-R

Werner, G.D.A., Strassmann, J. E., Ivens, A. B. F., Engelmoer, D.J.P., Verbruggen, E., Queller, D. C., Noe, R., Johnson, N. C., Hammerstein, P., and Kiers, E. T. 2014. Evolution of microbial markets. Proceedings of the National Academy of Sciences USA 111(4):1237-1244. https://doi. org/10.1073/pnas.1315980111

Westhoek, A., Field, E., Rehling, F., Mulley, G., Webb, I., Poole, P. S., and Turnbull, L. A. 2017. Policing the legumeRhizobium symbiosis: A critical test of partner choice. Scientific Reports 7(1):1419. https://doi.org/10.1038/ s41598-017-01634-2

Wilson, D. S. and Sober, E. 1989. Reviving the superorganism. Journal of Theoretical Biology 136(3):337-356. https://doi. org/10.1016/S0022-5193(89)80169-9

Yamaya-Ito, H., Shimoda, Y., Hakoyama, T., Sato, S., Kaneko, T., Hossain, M. S., Shibata, S., Kawaguchi, M., Hayashi, M., Kouchi, H., and Umehara, Y. 2018. Loss-of-function of ASPARTIC PEPTIDASE NODULE - INDUCED 1 (APN 1) in Lotus japonicus restricts efficient nitrogen-fixing symbiosis with specific Mesorhizobium loti strains. The Plant Journal 93(1):5-16. https://doi.org/10.1111/tpj.13759

Yang, X. and Fang, S. 2015. Practices, perceptions, and implications of fertilizer use in East-Central China. Ambio 44(7):647-652. https://doi.org/10.1007/s13280-0150639-7

Zheng, M., Zhou, Z., Luo, Y., Zhao, P., and Mo, J. 2019. Global pattern and controls of biological nitrogen fixation under nutrient enrichment: A meta-analysis. Global Change Biology 25(9):3018-3030. https://doi.org/10.1111/ gcb. 14705

Zilber-Rosenberg, I. and Rosenberg, E. 2008. Role of microorganisms in the evolution of animals and plants: The hologenome theory of evolution. FEMS Microbiology Reviews 32(5):723-735. https://doi.org/10.1111/j.15746976.2008.00123.x 